\title{
BMJ Open A review of the international Burn Injury Database (iBID) for England and Wales: descriptive analysis of burn injuries 2003-2011
}

\author{
Neophytos Stylianou, ${ }^{1}$ Iain Buchan, ${ }^{1}$ Ken W Dunn ${ }^{1,2}$
}

To cite: Stylianou N, Buchan I, Dunn KW. A review of the international Burn Injury Database (iBID) for England and Wales: descriptive analysis of burn injuries 2003-2011. BMJ Open 2015;5:e006184. doi:10.1136/bmjopen-2014006184

- Prepublication history and additional material is available. To view please visit the journal (http://dx.doi.org/ 10.1136/bmjopen-2014006184).

The subject matter of the paper has been previously presented to meetings of the British Burn Association in May 2013 and the European Burns Association in August 2013.

Received 23 July 2014 Revised 14 October 2014 Accepted 30 October 2014

CrossMark

For numbered affiliations see end of article.

\section{Correspondence to} Neophytos Stylianou; Neophytos.stylianou@ postgrad.manchester.ac.uk

\section{ABSTRACT}

Objective: To describe, for the first time, distribution (by geography, age, sex) and time trends in burn injury in England and Wales over the period that the international Burn Injury Database (BBID) has been in place.

Setting: Data from the iBID for the years 2003-2011 were used for a retrospective descriptive observational study of specialised services workload and admissions in England and Wales.

Participants: All patients who have been visited or admitted to the burn injury specialised health service of England and Wales during the time period 2003-2011. Data cleaning was performed omitting patients with incomplete records (missingness never exceeded $5 \%$ ).

Outcome measures: Workload, admissions, mortality, length of stay (LOS), geographical distribution, sex differences, age differences, total burn surface area, mechanism of Injury.

Results: During 2003-2011, 81181 patients attended the specialised burn service for assessment and admission in England and Wales. Of these, 57801 were admitted to the services. Males accounted for $63 \%$ of the total workload in specialised burn injury services, and females for $37 \%$. The median (IQR) burn surface area was $1.5 \%(3.5 \%)$. The most frequent reason for burn injury was scald (38\%). The median (IQR) age for all the referred workload for both genders was 21 (40). The overall mortality of the admitted patients was $1.51 \%$ and the median (IQR) LOS was 1 (5) days.

Conclusions: Mortality from burn injuries in England and Wales is decreasing in line with western world trends. There is an observed increase in admissions to burn services but that could be explained in various ways. These results are vital for service development and planning, as well as the development and monitoring of prevention strategies and for healthcare commissioning.

\section{INTRODUCTION}

Burns are usually injuries to the skin but can also directly injure the lungs and airways and occasionally can affect muscles, bones and other internal organs. Burns are injuries

\section{Strengths and limitations of this study}

- First time a clinical epidemiological review was performed and published.

- Routinely collected data can be used for epidemiological review of the injury.

- A specialised database is of vital importance to the service.

- Quality of the database is variable.

- Lack of socioeconomic analysis of burn injury.

caused by heat, electricity, radiation or corrosive substances and range from very minor to extremely severe. The severity of the injury is usually characterised by the extent of skin affected, anatomical site, depth of the injury, the age of the patient and the presence of coexisting disorders.

Minor burn injuries are treated within the community, but more severe burns require medical attention and usually hospitalisation in specialised departments with care provided by a multidisciplinary team, as this has been proven to offer the best possible outcome for the patient. ${ }^{1}$

In 2004, the WHO Global Burden of Disease report estimated that approximately 11 million people per year had burn injuries that were sufficient to seek medical attention -placing burn injury as the fourth most common substantial injury, just after road traffic accidents, falls and interpersonal violence. $^{23}$ Based on a recent estimate, $5 \%$ of the significant trauma workload in England and Wales is a result of burn injury. ${ }^{4}$

According to Roberts, ${ }^{5}$ unless the epidemiology of burns is well studied and documented in a population, prevention campaigns should not be launched. He stated that although many studies look at small areas within countries, there is still not enough information nationwide and worldwide to successfully design and implement a good 
prevention strategy. ${ }^{5}$ The priority of public health services regarding burn injuries must be bridging that gap. Until 2003, it was very difficult to assess the burden of burn injuries in the UK since there was a lack of a national monitoring system. In 2005, a national database was launched that had as its purpose the systematic collection of data from all burn services.

With implementation over the past decade of the recommendations contained in the National Burn Care Review, published in 2001, ${ }^{6}$ burn services in England and Wales have moved towards being organised in such a way that non-complex injuries are referred to burn facilities, more complex burns are referred to burn units and the most complex injuries to a small number of burn centres. There are specific guidelines which allocate each injury to the specific service. ${ }^{7}$ The arrangement of services has historically not been based on epidemiological data. According to a draft report on the specialised burn services of London, correct placement of the burn services has not yet been achieved and would require significant reorganisation if the epidemiological evidence was the sole basis for future arrangements.

Literature reviews identify very few papers describing the epidemiology of burn injuries in the UK population. Most papers describe admissions to individual burn services, attendance to National Health Service (NHS) Emergency Departments or describe the epidemiology of a subpopulation of the country. ${ }^{9-13}$

The only study which looked at the national epidemiology of burns was published at the end of 2013 describing the English NHS hospital admission trends by using data from Hospital Episode Statistics (HES) for the years 1991-2010. ${ }^{14}$ HES reflects mandated data collected about patients after being admitted to hospital. ${ }^{15}$ Coding of diseases and patient status is based on the International Classification Code (ICD) V.10, which, for burn injury as with most diseases, is insufficient and lacks codes to record important details. The only two codes that have an indication of the severity of the burn injury are T31 (burns classified according to the extent of body surface involved) and T32 (corrosions classified according to the extent of body surface involved), but they are still insufficient.

Therefore, healthcare professionals, mostly clinicians, who require more detailed information about their area of expertise, develop their own specialised highly detailed databases; ${ }^{16}$ such an example is the international Burn Injury Database (iBID), launched in April 2005 when services were asked to retrospectively provide data from January 2003. Data are collected from first contact with the burn service through rehabilitation and any late reconstruction procedure. Data are recorded by clinicians and nurses, which are then transferred into the database. These are analysed monthly and reports are sent back to the specific burn site with the summary of their activity over the past month. The data are centrally stored on an NHS server and access to them is given by special permission. ${ }^{17}$
It is very difficult to assess the true extent of a burn injury since it is so diverse that many sufferers do not seek medical help, but they are treated within the community. Therefore, the monitoring systems for burn injuries only record the most severe burns, which are the minority. One way to monitor the number of burn injuries is through the 'consumption' of the service. No research has been published to date on the monitoring of the workload the specialised burn service experiences, the hospital admissions trends and mortality caused by burn injury using data from the burn injury specialised services. The majority of the work undertaken so far has been conducted for NHS planning purposes but remains unpublished. The aim of this study is to provide a descriptive epidemiology and to identify and describe trends in burn injury for the years 2003-2011. This study provides some information on the impact of implementing the 2001 recommendations of 10 years later.

\section{METHODS}

Data were obtained from iBID and were broken down by: age groups; children, patients aged under 16 years age, adults, 16-65 and the elderly who are patients aged more than 65, gender as well as Primary Care Trusts (PCTs) and Local Health Boards (LHBs). PCTs were abolished in April 2013, but before that they were responsible for commissioning health and social care to the population of their allocated geographical area. For the time period of this analysis, the use of these local health services for geographical separation is appropriate.

For each type of descriptive epidemiology analysis, analogous data cleaning was performed to avoid the unnecessary loss of valuable information. Descriptive epidemiological analyses were performed on the workload, containing the admitted and non-admitted patients, as well as on the admissions to the service. All analyses were conducted using Stata, V.12.0. The local health services boundaries were provided by the Office of National Statistics. ${ }^{18}$

\section{RESULTS}

Trends of burns injury workload and admissions in England and Wales, 2003-2011

During the period 1 January 2003-31 December 2011, 81181 injuries were referred for assessment and admission to burn services in England and Wales of which 9689 were not acute injuries. Of those 81181 injuries, 57801 required admission to the service. Figure 1A shows the total workload of the burn services and figure $1 \mathrm{~B}$ indicates the trends of the patients admitted to the service in England and Wales for the period 2003-2011.

The workload of the burn injury service has increased by a scale factor of 2.5 over the period of investigation. From roughly 5500 cases in 2003, it increased to more than 13000 cases in 2011. The workload in the elder age group has remained relatively constant over the 

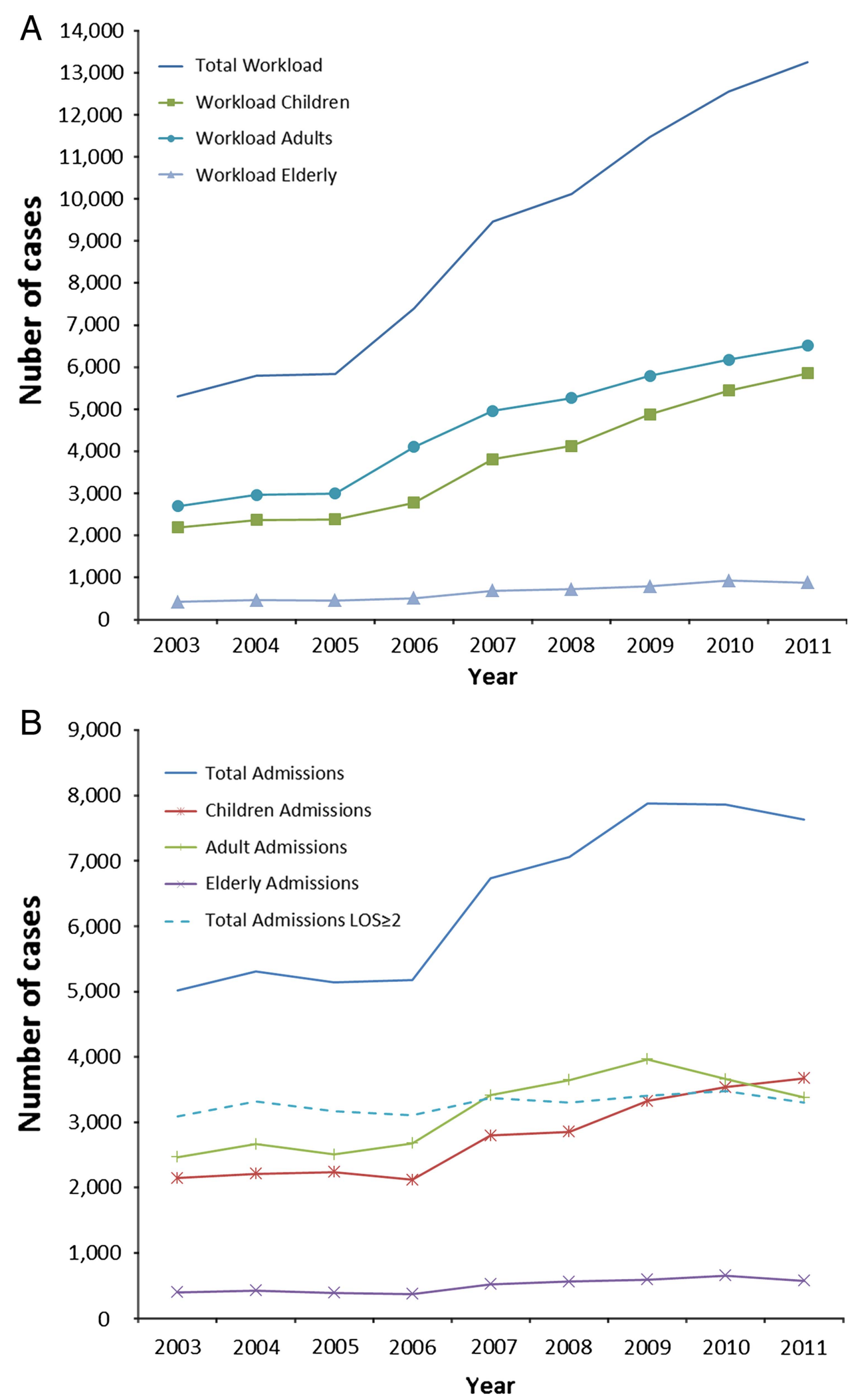

Figure 1 (A) Workload of burn injury specialised service in England and Wales for 2003-2011. (B) Admissions only to burn injury specialised service in England and Wales for 2003-2011.

years. The workload in the children and adult groups follows a comparable trend. Both are quite stable for the years 2003-2005, followed by an increase of an approximate scale factor of 1.5 for 2 years, and then the gradient of the line decreases, still indicating an increase in the workload but at a slower pace.

Admissions to the service show a similar trend to the workload trend. They are constant for a period of time and 


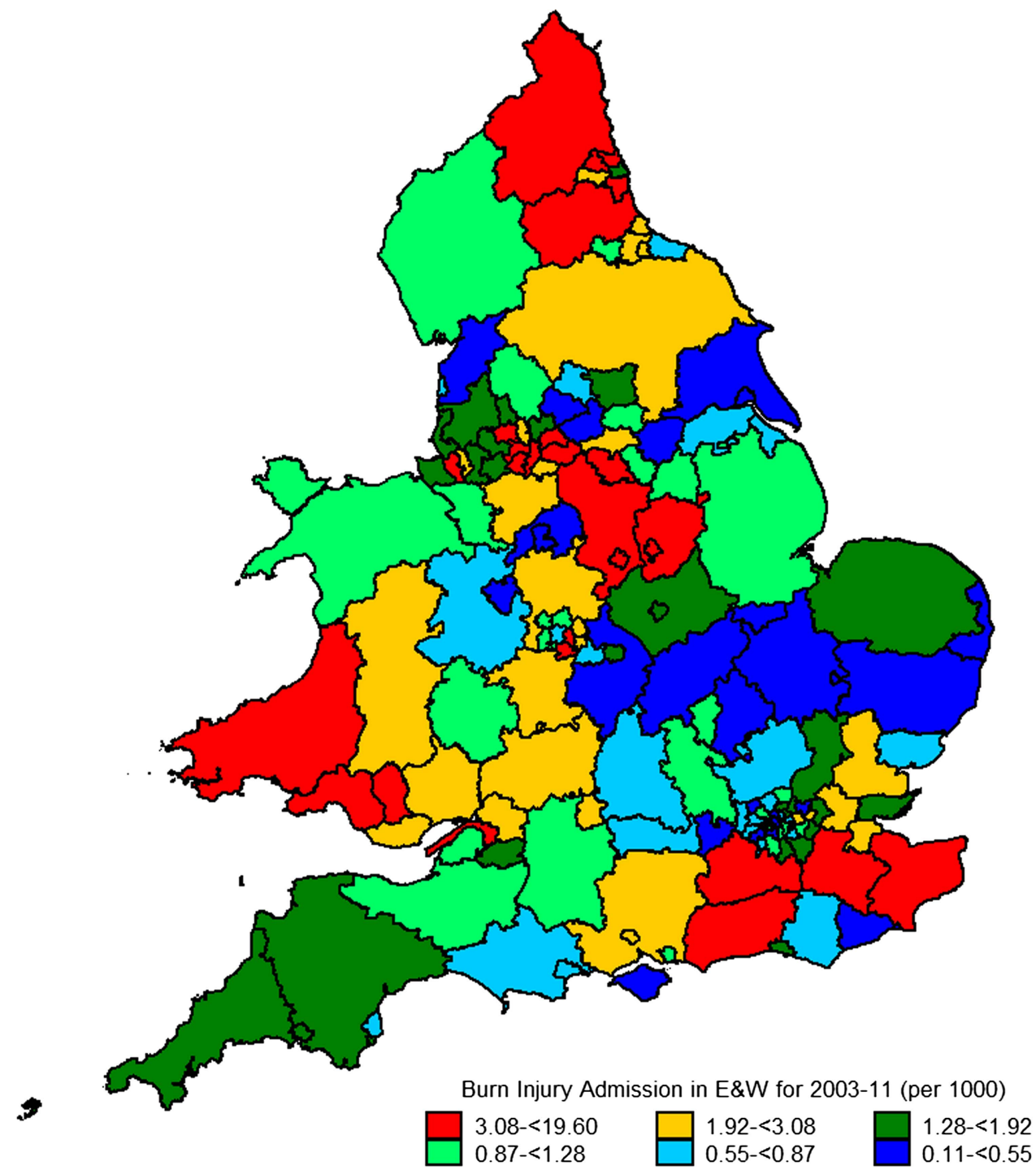

Figure 2 Population adjusted specialised burn injury admissions in England and Wales 2003-2011 based on geographical catchment area of each Primary Care Trust and Local Health Board (for ease to the reader in identifying each location, a map from the Office for National Statistics can be found in the online supplementary information ${ }^{19}$ ).

then demonstrate an increase. Overall, the increase in admissions rises after 2006 and lasts for 2 years where it plateaus at around 7500 admissions per year. The adult and children's admissions increased after 2006. Adult admissions reached their peak at almost 4000 admissions in 2009 when they dropped by almost 500 in the following 2 years. Children's admissions are showing an increasing trend after 2006. The elder age group follows a constant trend over the years of the study similar to the workload trend. From figure 1B, it can be clearly seen that the trends of people that were admitted for more than 1 day to the service are relatively constant over the time period under investigation.

\section{Geographical distribution of the workload of burn injury}

In 2003-2011, the total workload was 81181 patients: $8603(10.6 \%)$ in the Welsh burn services and 72578 (89.4\%) in England's burn services. England had 151 PCTs, and in Wales there were, after the 2007 Welsh
NHS reorganisation, 7 LHBs. The trust with the smallest workload (73) was the Westminster PCT and the one with the highest workload (2754), the Manchester teaching PCT. The mean (median, IQR) workload per trust in England was 480.72 (357 461). The LHB with the lowest number was Powys, whereas the one with the highest number was Abertawe Bro Morgannwg. The average (median, IQR) workload per health trust in Wales was 1315 (median 1356, IQR 956).

The crude numbers were standardised based on the population of each health trust. On figure 2A, a map of the total admissions adjusted per 1000 population of each catchment area of PCT and LHB is illustrated for both England and Wales for the time period 2003-2011 (in the online supplementary figure S1, a map from the Office for National Statistics (ONS) shows the names of each PCT and LHB in detail). The admissions ranged from $0.11 / 1000$ to $19.60 / 1000$ for the period 2003-2011. When adjusting for the population of each capture area, 
焉

হᄃ

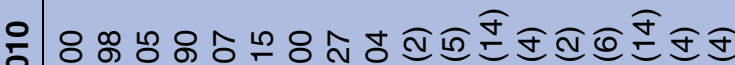

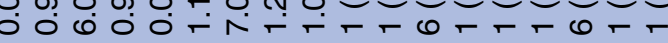

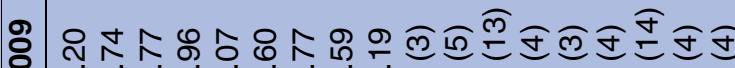

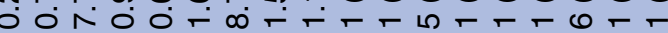

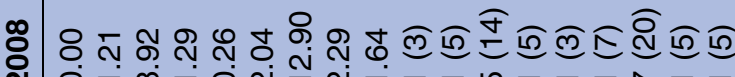
ำ

今̊

ㅊำ

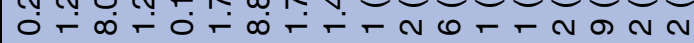

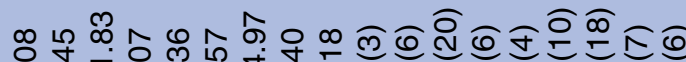

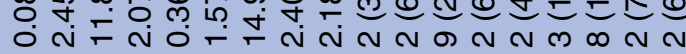

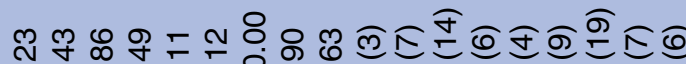

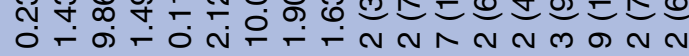

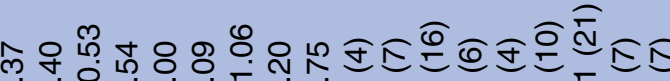

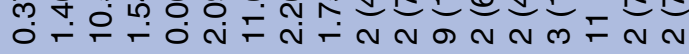

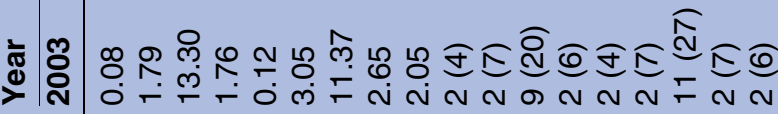

as obvious from the map, Wales burn injury admissions are on the high range of the data with all seven LHBs admissions ranging from $1.10 / 1000$ to $5.36 / 1000$.

The map shows that the lowest admissions for specialised burn care in England can be found in eastern and central England consisting of the Great Yarmouth and Waveney Teaching, Suffolk, Cambridgeshire, Peterborough, Bedfordshire and Warwickshire PCTs. Central and West London does not have as many admissions, whereas there are two health trusts in East London that lie on the high band compared with the others, Newham (2.14/1000) and Barking and Dagenham (2.02/1000). Croydon, Bromley, Havering and Bexley care trusts, all part of Southeast London, have 1.28-1.92 admissions per 1000.

There are four trusts in South England that lie within the highest band of admissions per 1000 population; these are West Sussex, Surrey, West Kent and Eastern and Coastal Kent. Bristol's PCT also lies on the highest band with 3.63/1000. Derbyshire and Nottinghamshire also suffer from high admissions. The majority of the Greater Manchester trusts fall within the highest bands, with the Manchester Teaching PCT having the highest number at 19.60/1000. North England also has high admission rates; Northumberland and Newcastle and County Durham are also on the highest band.

\section{Trends in outcomes following admission to a burn injury service}

Overall mortality for all the workload that the England and Wales burn services during 2003-2011 was 1.12\%. Thirty-three patients who were not admitted to the burn services had died over the study period. Those were acute injuries but were out patients and outreach patients. These patients were not admitted to the service but only seen by a clinician since they had more serious conditions and needed to be admitted to the appropriate ward for their condition. Half of them were aged more than 70 years while the vast majority of them were more than 80 years.

Of the patients admitted, 875 died in the hospital, resulting in a total in-hospital mortality of $1.51 \%$. Overall mortality in the burn service followed a downward trend as can be seen from table 1. Children had the lowest mortality of all admitted patients. Older patients had a higher mortality rate than other age groups. In all these years female mortality is higher than male mortality.

The length of stay (LOS) of patients within the burn service varied from 0 to 455 days. There were 16 patients who stayed within the burn service for more than 365 days. The median (IQR) LOS was 1 (5) day. Patients admitted to the hospital for 1 day or less accounted for $50 \%$ of the total admissions. The 75 th centile of admissions was 5 days or less in the hospital. As can clearly be seen from table 1, the elderly of both genders stayed in hospital for a longer period, whereas the age group that stayed in hospital for the shortest period of time were children. There is a decreasing trend in the hospitalisation period for all age groups and both genders over the period of the study. 
Table 2 General description of workload and admissions patients of the specialised burn injury service in England and Wales for the period 2003-2011

\begin{tabular}{|c|c|c|c|c|c|c|c|c|c|c|c|c|c|}
\hline \multirow[b]{2}{*}{ Year } & \multirow[b]{2}{*}{$\begin{array}{l}\text { Total } \\
\text { cases }\end{array}$} & \multicolumn{2}{|c|}{ Gender (\%) } & \multicolumn{3}{|c|}{ Age (median (IQR)) } & \multicolumn{3}{|c|}{ Age groups (\%) } & \multirow[b]{2}{*}{$\begin{array}{l}\text { TBSA \% } \\
\text { (median (IQR)) }\end{array}$} & \multicolumn{3}{|c|}{ Inhalation injury (\%) } \\
\hline & & Male & Female & Male & Female & Overall & $\begin{array}{l}\text { Children } \\
<16\end{array}$ & $\begin{array}{l}\text { Adults } \\
16-<65\end{array}$ & $\begin{array}{l}\text { Elderly } \\
\geq 65\end{array}$ & & Male & Female & Overall \\
\hline \multicolumn{14}{|c|}{ Workload } \\
\hline 2003 & 5310 & 66.78 & 33.22 & $23(36)$ & $18(43)$ & $22(38)$ & 41.30 & 50.77 & 7.93 & $2(5)$ & 2.34 & 1.59 & 2.09 \\
\hline 2004 & 5797 & 66.86 & 33.14 & $23(37)$ & $18(42)$ & 22 (39) & 40.88 & 51.11 & 8.00 & $2(5)$ & 1.91 & 1.93 & 1.91 \\
\hline 2005 & 5833 & 63.93 & 36.07 & $23(37)$ & $19(42)$ & $22(39)$ & 40.82 & 51.43 & 7.75 & $2(4)$ & 1.34 & 1.14 & 1.27 \\
\hline 2006 & 7396 & 64.59 & 35.41 & $24(35)$ & $20(42)$ & $23(39)$ & 37.61 & 55.50 & 6.88 & $2(4.1)$ & 1.28 & 0.99 & 1.18 \\
\hline 2007 & 9457 & 64.37 & 35.63 & $22(38)$ & $20(41)$ & $21(40)$ & 40.31 & 52.44 & 7.25 & $1.5(3.4)$ & 0.95 & 0.68 & 0.86 \\
\hline 2008 & 10125 & 63.47 & 36.53 & $23(38)$ & $19(41)$ & $21(39)$ & 40.78 & 52.06 & 7.16 & $1(3.5)$ & 0.76 & 0.95 & 0.83 \\
\hline 2009 & 11467 & 61.69 & 38.31 & $22(39)$ & $19(40)$ & $21(39)$ & 42.55 & 50.55 & 6.9 & $1(2.5)$ & 0.58 & 0.57 & 0.58 \\
\hline 2010 & 12547 & 59.03 & 40.97 & 22 (39) & $18(40)$ & $21(40)$ & 43.40 & 49.23 & 7.37 & $1(2.5)$ & 0.78 & 0.56 & 0.69 \\
\hline 2011 & 13249 & 60.34 & 39.66 & $21(39)$ & 18 (39) & $20(39)$ & 44.21 & 49.14 & 6.64 & $1(2.5)$ & 0.90 & 0.53 & 0.75 \\
\hline Total & 81181 & 62.72 & 37.28 & $22(38)$ & $19(41)$ & $21(40)$ & 41.70 & 51.09 & 7.21 & $1.5(3.5)$ & 1.07 & 0.84 & 0.99 \\
\hline \multicolumn{14}{|c|}{ Admissions } \\
\hline 2003 & 5018 & 66.88 & 33.12 & $22(36)$ & $16(42$ & $21(38)$ & 42.83 & 49.22 & 7.95 & $2.5(5)$ & 2.47 & 1.68 & 2.21 \\
\hline 2004 & 5304 & 67.38 & 32.62 & $23(37)$ & $17(43)$ & 22 (39) & 41.69 & 50.28 & 8.03 & $2.5(5)$ & 2.07 & 2.14 & 2.09 \\
\hline 2005 & 5139 & 64.08 & 35.92 & $21(38)$ & $16(40)$ & 20 (39) & 43.57 & 48.78 & 7.65 & $2.15(4.5)$ & 1.52 & 1.3 & 1.44 \\
\hline 2006 & 5173 & 65.32 & 34.68 & $23(38)$ & $18(43)$ & $21(40)$ & 40.98 & 51.81 & 7.21 & 2 (4.5) & 1.81 & 1.39 & 1.66 \\
\hline 2007 & 6733 & 65.44 & 34.56 & 22 (38) & 17 (42) & $21(40)$ & 41.53 & 50.71 & 7.77 & 2 (4) & 1.32 & 0.99 & 1.20 \\
\hline 2008 & 7061 & 64.76 & 35.24 & 23 (39) & $19(42)$ & $22(41)$ & 40.41 & 51.64 & 7.96 & $2(4)$ & 1.07 & 1.37 & 1.18 \\
\hline 2009 & 7881 & 63.22 & 36.78 & $22(40)$ & $18(41)$ & $21(40)$ & 42.18 & 50.29 & 7.54 & $2(3)$ & 0.82 & 0.83 & 0.82 \\
\hline 2010 & 7858 & 60.79 & 39.21 & $22(40)$ & $17(41)$ & $20(40)$ & 45.02 & 46.61 & 8.36 & $2(3)$ & 1.21 & 0.88 & 1.08 \\
\hline 2011 & 7634 & 61.66 & 38.34 & $20(40)$ & 12 (39) & 17 (39) & 48.15 & 44.28 & 7.57 & $1.5(3.2)$ & 1.51 & 0.96 & 1.30 \\
\hline Total & 57801 & 64.09 & 35.91 & $22(38)$ & $17(41)$ & $21(40)$ & 43.09 & 49.12 & 7.79 & $2(4)$ & 1.47 & 1.2 & 1.38 \\
\hline
\end{tabular}


Table 3 Mechanism of burn injury for non-admitted, admitted patients and total workload of the service, 2003-2011

\begin{tabular}{|c|c|c|c|c|c|c|c|}
\hline \multirow[b]{2}{*}{ Patient status } & \multirow[b]{2}{*}{$\begin{array}{l}\text { Injury } \\
\text { mechanism }\end{array}$} & \multicolumn{3}{|l|}{ Male (\%) } & \multicolumn{3}{|c|}{ Female (\%) } \\
\hline & & $\begin{array}{l}\text { Children } \\
<16\end{array}$ & $\begin{array}{l}\text { Adult } \\
16-<65\end{array}$ & $\begin{array}{l}\text { Elderly } \\
\geq 65\end{array}$ & $\begin{array}{l}\text { Children } \\
<16\end{array}$ & $\begin{array}{l}\text { Adult } \\
16-<65\end{array}$ & $\begin{array}{l}\text { Elderly } \\
\geq 65\end{array}$ \\
\hline \multirow[t]{9}{*}{ Non-admission } & Flame & 4.13 & 16.55 & 14.17 & 2.64 & 9.11 & 6.39 \\
\hline & Flash & 2.09 & 9.90 & 4.30 & 0.73 & 2.18 & 1.94 \\
\hline & Contact & 43.44 & 21.85 & 23.73 & 41.25 & 24.74 & 26.25 \\
\hline & Scald & 42.03 & 27.13 & 33.76 & 48.36 & 47.86 & 52.22 \\
\hline & Chemical & 1.64 & 14.52 & 10.51 & 1.384 & 6.49 & 3.06 \\
\hline & Electrical & 0.78 & 2.67 & 1.75 & 0.37 & 1.07 & 0.83 \\
\hline & Radiation & 1.31 & 1.42 & 3.19 & 0.86 & 2.24 & 1.53 \\
\hline & Other & 1.80 & 1.81 & 2.39 & 1.75 & 1.67 & 0.97 \\
\hline & Unknown & 2.78 & 4.88 & 6.21 & 2.66 & 4.64 & 6.81 \\
\hline \multirow[t]{9}{*}{ Admissions } & Flame & 7.76 & 27.10 & 27.60 & 6.23 & 23.44 & 21.51 \\
\hline & Flash & 4.60 & 14.95 & 7.69 & 1.20 & 3.93 & 3.68 \\
\hline & Contact & 21.17 & 14.84 & 19.82 & 19.12 & 18.54 & 19.33 \\
\hline & Scald & 52.90 & 16.95 & 26.21 & 60.17 & 35.66 & 42.92 \\
\hline & Chemical & 1.36 & 11.81 & 5.91 & 1.63 & 5.65 & 1.18 \\
\hline & Electrical & 1.05 & 4.19 & 1.96 & 0.63 & 1.37 & 0.36 \\
\hline & Radiation & 0.70 & 0.80 & 1.04 & 0.52 & 1.55 & 1.32 \\
\hline & Other & 1.95 & 2.50 & 3.17 & 2.29 & 2.33 & 2.50 \\
\hline & Unknown & 8.52 & 6.86 & 6.61 & 8.20 & 7.53 & 7.21 \\
\hline \multirow[t]{9}{*}{ Total workload } & Flame & 6.82 & 24.05 & 24.72 & 5.25 & 18.11 & 17.78 \\
\hline & Flash & 3.95 & 13.28 & 6.97 & 1.07 & 3.28 & 3.25 \\
\hline & Contact & 26.91 & 16.87 & 20.66 & 25.17 & 20.84 & 21.03 \\
\hline & Scald & 50.1 & 19.89 & 27.83 & 56.94 & 40.20 & 45.21 \\
\hline & Chemical & 1.44 & 12.59 & 6.90 & 1.56 & 5.96 & 1.64 \\
\hline & Electrical & 0.98 & 3.75 & 1.91 & 0.56 & 1.26 & 0.45 \\
\hline & Radiation & 0.86 & 0.98 & 1.50 & 0.61 & 1.81 & 1.37 \\
\hline & Other & 1.91 & 2.30 & 3.00 & 2.14 & 2.08 & 2.12 \\
\hline & Unknown & 7.04 & 6.29 & 6.52 & 6.69 & 6.46 & 7.11 \\
\hline
\end{tabular}

\section{General description of burn injury}

As previously mentioned, the workload to the burn service increased during the time of the study. The same was true about admissions to the burn services with the difference that the admissions did not have an everincreasing trend but stabilised after 2009. A general description of the patients who were referred and admitted to the specialised burn services can be seen in table 2. The gender differences are the same in both workload and admission data. The ratio of males to females was 1.7:1 for workload data set and 1.8:1 for admissions. Men had the same median age in both admissions and workload data sets. Women who were admitted to the service had a median age of 17 but the total visits to the service had a median age of 19 . The median ages for both genders are relatively constant over the years of the study.

Overall workload as well as patients admitted to the burn services for all the years of the study have approximately a stable trend over time when looked at the age group level. For the time period of the study, $42 \%$ of the total workload were children and similarly $43 \%$ of the admitted patients were attributed to the children age group. Of the total service workload, $51 \%$ were adults, whereas $49 \%$ of those admitted belonged to the adult age group. The remaining, approximately $7 \%$ for both workload and admissions, is attributed to the elder age group.

The median total burn surface area (TBSA) was again relatively constant across the years of the study. It ranged from $1 \%$ to $2 \%$ with an overall median (IQR) of $1.5 \%$ (3.5). The admitted patients had a slightly higher median TBSA; it ranged from $1.5 \%$ to $2.5 \%$ with an overall median (IQR) of 2 (4).

Inhalation injury is a computed variable. It is computed based on whether the medical record states moderate or severe inhalation injury and/or whether the patient was intubated and had mechanical ventilation. In all years inhalation injury was slightly higher in male patients compared to females. It is showing a downward trend. Higher proportions of patients with inhalation injury were observed in the admitted patients compared with the data set containing the full service workload.

\section{Mechanism and causation of burn injury}

Overall contact, flame and scald were the predominant mechanisms for burn injury as can be seen from table 3. Scald was the most common cause of burn injury among all non-admitted patients. It was also the most common cause of admission in all female age groups as well as in male children and the elderly. The second most common cause of burn injury in total 
and non-admitted female patients was contact burns. In admitted female patients, this was true only in the children's age group, but in the adult and elderly, contact burn was the third most common cause with flame burn being the second most common cause. Flame was the third most common mechanism of burn injury in females in the overall and non-admitted data sets. The most common mechanism of burn in nonadmitted male patients was scald, except in children in whom it was a close second with contact burn being the most frequent cause. In the admitted male patients, scald was the most common mechanism in children, but in the adult and elderly age group it was flame.

\section{DISCUSSION}

The analyses indicate that there is a greater proportion of children and young adults being referred as well as admitted to a burn service, which indicates a potential greater risk for those demographic groups, but further statistical analysis is needed to establish these relationships. This follows what was already known about burn injury; the age groups that are more susceptible are children and the elderly. ${ }^{20}$ Although the referral and admission to the service is roughly the same for adults and children, adults have higher mortality rates as well as a higher median LOS. This indicates that the severity of the injury is higher in the adult age group, which itself is explained by the different mechanisms of burn injury seen between the age groups. The majority of injuries that were referred as well as admitted to the service in the children's age group were caused by a scald $(52.86 \%$ of children's workload, $55.87 \%$ of children's admissions). This high admission rate for children can also be illustrative of a more cautious, highly preventative approach that the health system undertakes in order to provide the best possible care to children as well as a high concern from the service regarding child protection issues.

We can see an obvious difference in the mechanism of burn injury that is directly related to the sex difference. There is a big difference between chemical and flash burns in the two sexes. An explanation for this could be that more men than women hold jobs that carry a risk of burn injury. It may also be that men perform more household maintenance activities with a higher risk of chemical, flash and electrical injury. From the analysis, we observe that the most common mechanism causing burn injury in both sexes is scald. Overall scalds account for $35 \%$ of the total population admitted. Flame burns are the third most common cause of injury for admission and this could be the effect of fire alarms being installed..$^{21}$

Geographical analysis of burn injury based on the PCT of residence indicates a potential form of health inequalities. It should be noted here that the PCTs in most major cities are usually adjacent to major burn services and this may reflect an increased admission rate based on the fact that those services may admit local minor injuries, whereas only more significant injuries are sent to more distant sites. The opposite is also a valid argument; services that have a wide, mostly rural catchment area, where patients need to travel a substantial distance to receive care, tend to admit those patients as it is more practical than expecting to patients to make multiple journeys for wound dressings and review.

The WHO estimates that approximately 195000 people died from fire-related injuries in 2008 worldwide,${ }^{22}$ which is a decrease of almost $40 \%$ in relation to 2004 when the WHO estimated burns by fire-related injuries to be $310000 .^{23}$ The results from this analysis indicate that mortality in the specialised burn services of England and Wales has followed the trends seen in the rest of the developed world. ${ }^{24-26}$ Although mortality is not the definitive outcome of a condition and is only one consequence of burn injury, trauma remains the number one cause of death in the UK in the first 40 years of life. ${ }^{27}$

Mortality during the past four decades was decreased mainly because of improved medical knowledge on the pathophysiology of burn injuries, which in turn results in better therapy that increases survival rates. Since no major advancement was been made in burn treatment during the past decade, the observed mortality decrease in England and Wales could be attributed to the reorganisation of burn services with implementation of the recommendations of the National Burn Care Review: Strategy for Burn Injury in 2001 with the centralising of the management of complex burn injuries into a smaller number of specialised burn services.

Burn injury admissions in England and Wales to specialised burn services show an increase over the study period. This increase mirrors the findings of the research performed by Brewster et al, ${ }^{14}$ which used data from HES. The overall population of England and Wales for all age groups and all years has increased over the years of study by $6 \%$, but this increase was not evenly distributed geographically. ${ }^{28}$ However, this could not be the explanation for the increased admissions in burn services, since admission numbers increased by almost a scale factor of 3 over the years. With the publication of the National Burn Care Review: Strategy for Burn Injury in 2001, the NHS had new guidelines regarding burn injury admissions. This increase observed by both HES data as well as iBID data could indicate that the national admission criteria were either more strictly adhered to, leading to more admissions, or the previous regional criteria were not well defined or communicated. It is known that there was no monitoring of adherence prior to the creation of iBID in 2005.

Some of the increase in referrals and admissions over the years could also be an artefact of the delayed uptake of the database rather than a pure increase in admissions. The iBID database was mandated in 2005 and services were asked to manually input their records for the previous 2 years. Initially, only admissions to the service had to be recorded, but some services saw an opportunity to fuel service improvement and the database was used as a tool in achieving that by recording all burn 
service referrals and activity in it. This practice is now more widespread. As a result, we have an increasing input into the database which is not reflective of a true increase in incidence, but which we believe is a result of behaviour change of the services. This differential in the way activity is recorded has given rise to some confusion about what the true level of demand is as some services appear to have a policy to discharge patients early, subsequently leading to readmissions for ongoing care, which in turn appear to duplicate admissions. To clarify the commissioning consequences, further analysis work is being undertaken to compare HES data with that from iBID. This will minimise the risk of double counting.

Another possible reason for the observed increased admissions could be data quality. As mentioned earlier, uptake of the database was gradual and some services were at first reluctant to collect and submit their data. This led to some poor data quality issues in the first years of the database. This was represented by the record completeness which gradually improved over time. This is the subject of a separate study.

\section{Strengths}

The use of iBID in this study demonstrates the usefulness of routinely collected data. Data already collected may have an impact on research as well as formulating prevention strategies. This is the first time data have been extracted from iBID to be used for descriptive epidemiology of the injury. The purpose of iBID was to provide data that will be used for service improvement, and this paper is the start of defining this surveillance mechanism.

A specialised service database such as iBID is needed in order to specifically and accurately measure the actual numbers of burn injuries which are admitted to the health services in England and Wales. HES data can be used to find the actual numbers of hospital admissions caused by burn injuries but is insufficiently detailed to allow descriptive epidemiology.

\section{Limitations}

Data for the years 2003-2009 are of variable quality. This is because the database was put into use in 2005 when most but not all services contributed; the uptake of the database has continued to climb gradually. From 2005 to 2007 , services may not have prioritised use of the database as a means to monitor care. From 2009, there are similar numbers of hospital admissions on iBID when compared with HES. Therefore, expert analysis and careful interpretation of the data are needed when attempting to describe the epidemiology of burn injury.

Another limitation of this study is the lack of socioeconomic analysis. The database could not be used for analysis of burn injuries in relation to the socioeconomic status and the Index of Multiple Deprivation of the patients referred and admitted to the services. Changes to the database software in 2012 have since made this possible and will be the subject of another study.

\section{CONCLUSION}

Approximately 13000 injuries which require hospital attention occur every year in England and Wales. As with any clinical information system, iBID also exerts some drawbacks related to data quality, but even HES data that are used by the NHS and considered as the gold standard of routine data experience the same issues with data quality. ${ }^{29}$ iBID, as a tool for Information and Communication Technology, proves to be a very effective surveillance mechanism and efforts should be made to achieve better data quality and maintain its mandated status. Information and Communication Technologies aim to improve the quality and efficiency of health services; thus, iBID should be continued to be used as it is the most detailed database of such injury. Mortality is gradually decreasing indicating an improving approach on saving lives from burn injuries. Policies regarding population health protection should be focused on those areas and those subpopulations in order to minimise the effect of such injuries on them.

Author affiliations

${ }^{1}$ Centre for Health Informatics, Institute of Population Health, University of

Manchester, Manchester, Lancashire, UK

${ }^{2}$ University Hospital South Manchester, Manchester, UK

Acknowledgements The University of Manchester Library services for providing Open Access Funding fees.

Contributors NS analysed all data and wrote the original manuscript with contributions from KWD. KWD provided the data. IB helped contents of the paper. All authors commented on the manuscript. NS, IB and KWD conceived the idea for the study.

Funding The authors would like to express their gratitude for the funding provided from the Margaret Miller Research Fund administered by the British Burn Association and the Healing Foundation.

\section{Competing interests None.}

Provenance and peer review Not commissioned; externally peer reviewed.

Data sharing statement Statistical code available from the corresponding author. Data set available on request from the Specialised Burn Injury Service and iBID.

Open Access This is an Open Access article distributed in accordance with the Creative Commons Attribution Non Commercial (CC BY-NC 4.0) license, which permits others to distribute, remix, adapt, build upon this work noncommercially, and license their derivative works on different terms, provided the original work is properly cited and the use is non-commercial. See: http:// creativecommons.org/licenses/by-nc/4.0/

\section{REFERENCES}

1. Al-Mousawi AM, Mecott-Rivera GA, Jeschke MG, et al. Burn teams and burn centers: the importance of a comprehensive team approach to burn care. Clin Plast Surg 2009;36:547-54.

2. WHO. The global burden of disease 2004. Geneva, 2008.

3. Heimbach D. Burn patients, then and now. Burns 1999;25:1-2. http://www.ncbi.nlm.nih.gov/pubmed/10090377 (accessed 17 Jan 2012).

4. Kalson NS, Jenks T, Woodford M, et al. Burns represent a significant proportion of the total serious trauma workload in England and Wales. Burns 2012;38:330-9.

5. Roberts AH. Burn prevention-where now? Burns 2000;26:419-21. http://www.ncbi.nlm.nih.gov/pubmed/10812262

6. Dunn KW. Standards and Strategy for Burn Care. 2001. http://www. ibidb.org/downloads-mainmenu-28/cat_view/14-general-reports (accessed 14 Oct 2011). 
7. National Network for Burn Care. National Burn Care Referral Guidance. 2012.

8. London Health Programmes, Specialised Burns Project. Specialised burns model of care-draft outline. London, 2011.

9. Wilkinson E. The epidemiology of burns in secondary care, in a population of 2.6 million people. Burns 1998;24:139-43.

10. Dunn KW, Armfield R. The epidemiology and continued monitoring of burn injury in England and Wales. Inj Prev 2010;16:A211. http:// www.safety2010.org.uk/File/presentations/J1- Ken Dunn.pdf (accessed 5 Oct 2011)

11. Lawrence JC. Some aspects of burns and burns research Birmingham Accident Hospital 1944-93: A.B. Wallace Memorial Lecture, 1994. Burns 1995;21:403-13.

12. Rajpura A. The epidemiology of burns and smoke inhalation in secondary care: a population-based study covering Lancashire and South Cumbria. Burns 2002;28:121-30.

13. Rawlins JM, Khan AA, Shenton AF, et al. Epidemiology and outcome analysis of 208 children with burns attending an emergency department. Pediatr Emerg Care 2007;23:289-93. http://journals.Iww.com/pec-online/Abstract/2007/05000/

Epidemiology_and_Outcome_Analysis_of_208_Children.3.aspx (accessed 25 Nov 2011).

14. Brewster CT, Coyle B, Varma S. Trends in hospital admissions for burns in England, 1991-2010: a descriptive population-based study. Burns 2013;39:1526-34. http://www.sciencedirect.com/science/ article/pii/S0305417913003197 (accessed 27 Dec 2013).

15. HES Online: Hospital Episode Statistics. 2012. http://www.hesonline nhs.uk/Ease/servlet/ContentServer?sitelD=1937 (accessed 20 Mar 2012).

16. Sharp J. The quality of nationally submitted health and social care data. Anual Report. England: Experimental Statistics, 2013.
17. International Burn Injury Database. http://www.ibidb.org/ (accessed 1 May 2014).

18. ONS Geography ons. geography@ons. gsi. gov. u. UK map collection. http://www.ons.gov.uk/ons/guide-method/geography/ beginner-s-guide/maps/index.html (accessed 29 Apr 2014).

19. ONS. Primary Care Georgraphy. 2012. http://www.ons.gov.uk/ons/ index.htm

20. Peck MD. Epidemiology of burns throughout the world. Part I: distribution and risk factors. Burns 2011;37:1087-100.

21. Wood S, Bellis MA, Atherton J. Burns: a review of evidence for prevention from the UK focal point for violence and injury prevention. 2010.

22. WHO. Global burden of disease 2008 summary tables. Geneva, 2008. http://www.who.int/healthinfo/global_burden_disease/ estimates regional/en/index.html (accessed 2 Nov 2011).

23. WHO. Global burden of disease 2004 summary tables. Geneva, 2004. http://www.who.int/healthinfo/global_burden_disease/ estimates regional/en/index.html (accessed 3 Nov 2011).

24. WHO. A WHO plan for burn prevention and care. Geneva, 2008. http://whqlibdoc.who.int/publications/2008/9789241596299_eng.pdf (accessed 23 Nov 2011).

25. National Burn Reposiroty. National Burn Repository: report of data from 2002-2011. 2012.

26. Muller MJ, Pegg SP, Rule MR. Determinants of death following burn injury. Br J Surg 2001;88:583-7.

27. British Medical Association. Injury prevention. London, 2001.

28. Office for National Statistics. Population Estimates for England and Wales, Mid-2002 to Mid-2010 Revised (National). 2012.

29. Spencer SA, Davies MP. Hospital episode statistics: improving the quality and value of hospital data: a national internet e-survey of hospital consultants. BMJ Open 2012;2:e001651. 
Correction: A review of the international burn Injury

Database (iBID) for England and Wales: descriptive analysis

of burn injuries 2003-2011

Stylianou N, Buchan I, Dunn KW. A review of the international Burn Injury Database (iBID) for England and Wales: descriptive analysis of burn injuries 2003-2011. BMJ Open 2015;5:e006184. doi: 10.1136/bmjopen-2014-006184.

This article was previously published with error in Competing interests.

The burn injury database is funded by NHS England and is managed as part of his NHS contract by Mr Dunn who is medical director of the iBID and co-chair of the Burn Care Informatics Board that oversees the use of the iBID data.

Open access This is an open access article distributed in accordance with the Creative Commons Attribution Non Commercial (CC BY-NC 4.0) license, which permits others to distribute, remix, adapt, build upon this work non-commercially, and license their derivative works on different terms, provided the original work is properly cited, appropriate credit is given, any changes made indicated, and the use is non-commercial. See: http://creativecommons.org/licenses/by-nc/4.0/.

(c) Author(s) (or their employer(s)) [year]. Re-use permitted under CC BY-NC. No commercial re-use. See rights and permissions. Published by BMJ.

BMJ Open 2019;9:e006184corr1. doi:10.1136/bmjopen-2014-006184corr1 